\title{
EXPLORING VERTICAL WILDERNESS IN THE ACOUSTIC ENVIRONMENT
}

\section{DERRICK TAFF $\uparrow$ LAUREN ABbotT $\uparrow$ PETER NEWMAN The Pennylvania State University $\downarrow$ State College, PA}

\begin{abstract}
$\uparrow \quad$ ABSTRACT
Hearing sounds of nature is an important motivation for visitors to National Parks, such as Grand Teton National Park (GRTE; Newman et al. 2015). Furthermore, managers are required to provide park visitors with an enjoyable soundscape experience. In 2006, Pilcher and Newman conducted a study on visitor perceptions of soundscapes in highly trafficked locations in GRTE, the Jenny Lake boat dock and Inspiration Point. While this study used similar methods, it aimed to better understand the influence of soundscapes to a unique visitor group -climbers on the Grand Teton. This iconic climbing destination is located in an area that is potentially susceptible to anthropogenic or human caused noise interruptions because of its proximity to an airport and heavily used highways. In the summer of 2015 researchers from Penn State University used a combination of qualitative interviews and listening exercises with climbers to identify sounds that were being heard during their climbing experience and their emotions related to those sounds. These data provide managers with information about sounds that could be prioritized when managing for an optimal soundscape experience.
\end{abstract}

\section{$\downarrow$ INTRODUCTION}

Noise, or the unwanted sound commonly associated with vehicle traffic, construction and airplanes, is on the rise in national parks (Lynch et al. 2011). In a place where human caused environmental impacts are kept to a minimum, natural sound is becoming overshadowed by human induced noise. According to the U.S. National Park Service (NPS 2006), "noise levels in park transportation corridors today are at 1,000 times the natural level." National parks and wilderness areas are places where one could expect to find silence or escape from noisy urban

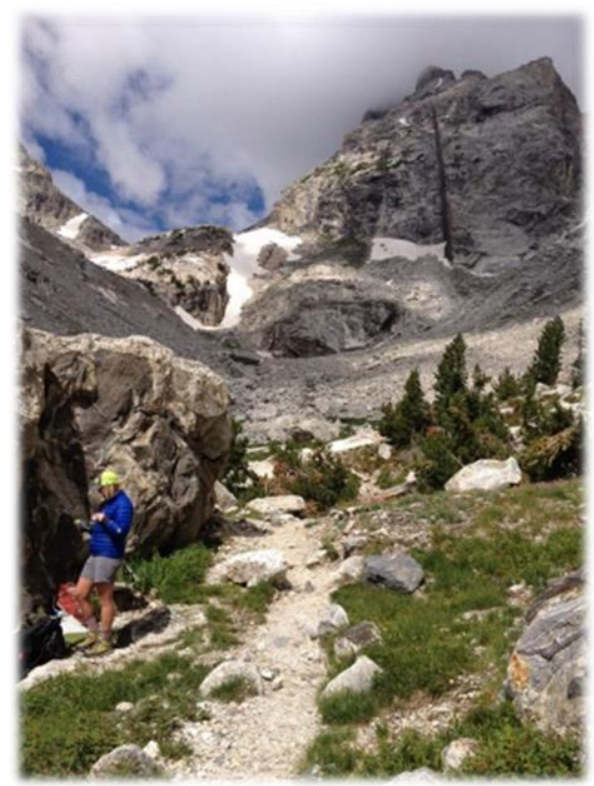

Figure 1. Researcher collecting data at the Meadows Site.

environments. In fact, enjoying sounds of nature, silence and escaping noise are often the most common motivations for visitors to parks and protected areas (Driver et al. 1991). With increased visitation to these areas, the amount of unwanted sounds from traffic, airplanes, helicopters, and people, has also increased, thus becoming a topic of concern. The NPS Soundscape Management Policy 4.9 states "the service will take action to prevent or minimize all noise that, through frequency, magnitude, or duration, adversely affects the natural soundscape or other park resources or values..." (NPS 2006). National park managers are taking steps to understand acceptable levels of noise and to mitigate noise so that natural sounds are not compromised. The purpose of this study was to investigate the types of sounds heard by climbers during their experience on the Grand Teton in GRTE and their perceptions of sounds. 
The summit of the Grand Teton is one of North America's most desirable mountaineering destinations. This 13,770 foot peak has a rich climbing history and attracts both advanced and novice climbers craving a more magnificent view of the Teton Range. Since the mountain was first summited in 1898, climbing on the Grand Teton has grown in popularity. There are two climbing concessions that operate guided trips to the summit year round. Because this area has faced growing use, it is challenging to provide quality visitor experiences that depend on high-caliber resource and social conditions.

The Garnet Canyon trail is frequently used by climbers approaching the Grand Teton and is subject to aircraft and traffic noise given its proximity to the Jackson Hole Airport and two major highways. Additionally, this area of the park is within a recommended wilderness area and is managed by the National Park Service (NPS) as wilderness. Federal wilderness areas are expected to provide "outstanding opportunities for solitude or a primitive and unconfined type of recreation" (National Wilderness Preservation Act 1964, Section 2c). This location is unique in that there is a combination of high climbing use and human caused noise within proposed wilderness --- impacts that may counteract a desired wilderness experience.

Earlier studies have identified the impacts of anthropogenic or manmade sounds to visitors to National Parks (Kariel 1990, Marin et al. 2011, Pilcher et al. 2009, Taff et al. 2015). Rock climbers are a unique community of recreationists and to date no study has examined the influence of sounds on climbers. Taff et al. (2015) interviewed mountaineers on Mount McKinley in Denali National Park to inform managers on their perceptions of social and resource conditions in this designated wilderness area. The research determined mountaineers place an emphasis on sound. Tarrant et al. (1995) evaluated the effects of overflights on visitors to wilderness areas in Wyoming. This study used a dose exposure survey technique to gain an understanding of how visitor characteristics influence evaluations of overflights. Researchers concluded that respondents had strong negative attitudes towards hearing overflights and were slightly more affected by hearing overflights than seeing them. Levels of solitude and tranquility were also decreased by sounds of overflights.

The Grand Teton is in a location that is potentially susceptible to anthropogenic sound given its proximity to the airport and highways. This is an ideal place to examine the influence of sounds, both natural and anthropogenic, to rock climbers. This project aims to provide managers with baseline information about the sound impacts in Garnet Canyon and the Grand Teton.

\section{$\downarrow \quad$ STUDY AREA}

This study was conducted with climbers who had used the Garnet Canyon trail to access the Grand Teton. This area was chosen because of its proximity to the Jackson Hole Airport, as well as major roads within the park. With help from NPS staff, two separate sites were chosen for a listening exercise and associated survey.

The 3 Mile Junction site is located in an area closer to anthropogenic sound sources. At this site, it was possible to view roads within the park and the Jackson Hole Airport. The Meadows site was further into the backcountry and the Garnet Canyon (See Figure 2). The 3 Mile Junction site is roughly 3 miles from the trailhead and the Meadows site is roughly 5.2 miles from the trailhead. Two different sites were chosen so that the researchers could analyze perceptions of sound from a site presumed to be more natural (the Meadows) and a site presumed to be less natural (the 3-Mile Junction).

\section{$\downarrow \quad$ METHODS}

In order to effectively develop indicators and related thresholds for acceptable amounts of noise heard and to understand the feelings associated with sounds heard by climbers, two separate methods were used: 1) qualitative interviews with climbers who have recently attempted or successfully summited Grand Teton, and 2) an in situ listening exercise and accompanying survey. This study used qualitative interviews to better understand the types of sounds climbers were hearing throughout their experience on the Grand Teton. The listening exercises and surveys provide managers with information about sounds heard at the two specific sites that were chosen, while the qualitative interviews provide information about sounds heard at other locations throughout the approach and climb on the Grand Teton.

\section{Phase one: Climber qualitative interviews}

Thirty-three climbers were interviewed through 18 semi-structured $(n=18)$ qualitative interviews. They were conducted with climbers after their climb on the Grand Teton from 7/3/15 to 7/12/15 with a $90 \%$ response rate. All respondents were interviewed within 24 hours of returning from their 


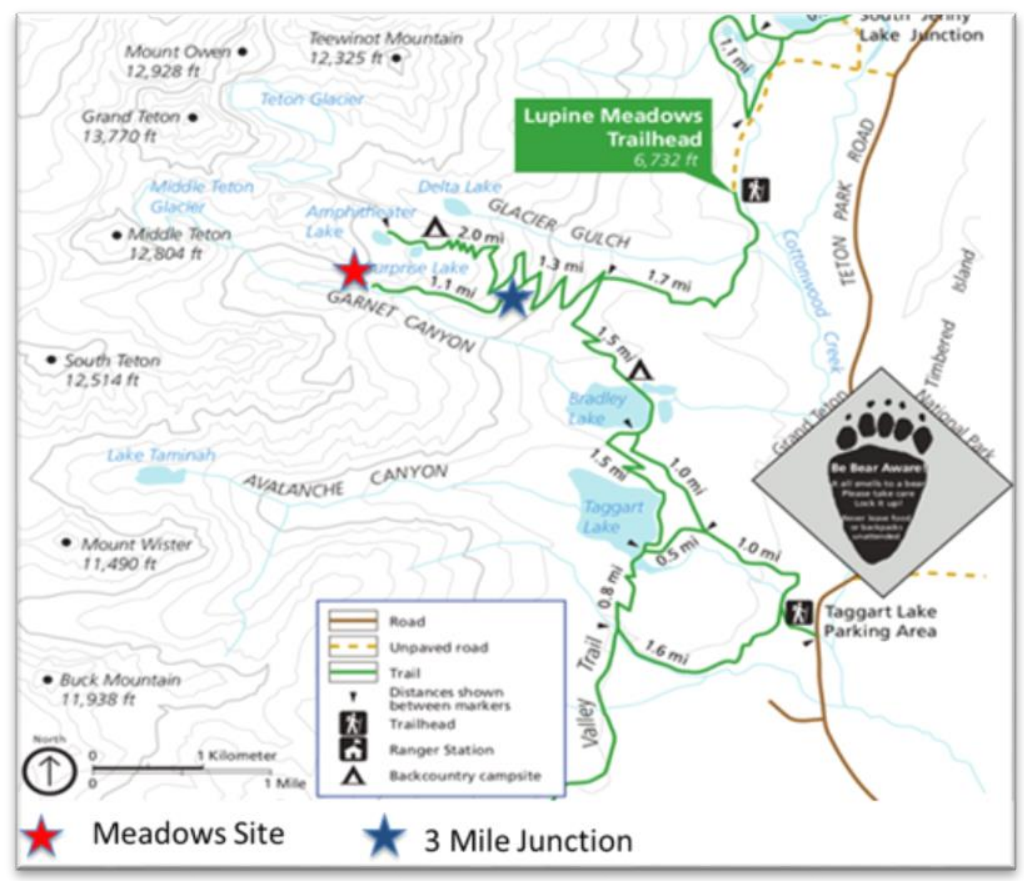

Figure 2. Study area map

climb on Grand Teton. Interviews ranged from 7 minutes to 22 minutes. All interviews were conducted within GRTE, at two locations, the Lupine Meadows Trailhead parking lot or the American Alpine Club Climbers' Ranch.

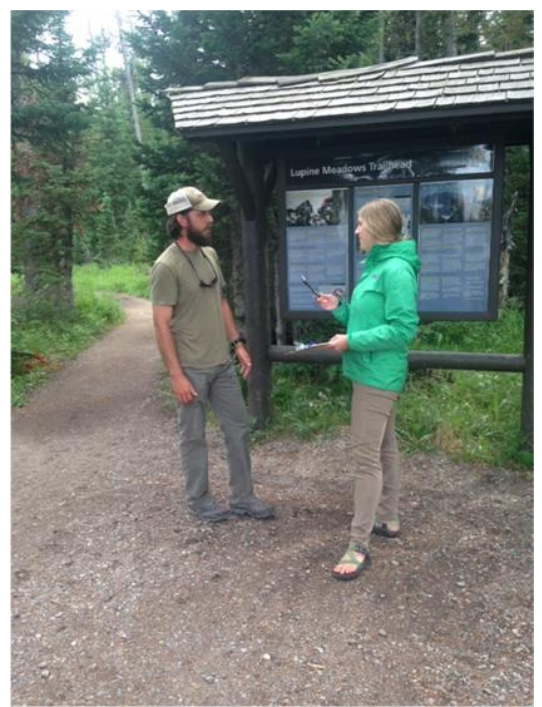

Figure 3. Researcher Lauren Abbott at the Lupine Meadows Trailhead.

Interview questions were developed based on a similar study that had been conducted with mountaineers on Mount McKinley in Denali National Park and Preserve (Taff et al. 2015). Interviews were recorded and transcribed verbatim. The purpose of the interviews was to identify sounds heard by climbers and determine their interpretations of sounds, therefore the data were treated as exploratory. Rather than seeking to define theoretical implications, interview questions were analyzed by inductively reviewing transcripts and determining reoccurring themes (Bogdan and Biklen 1998). The interview began by asking climbers questions about their motivations for climbing the Grand Teton and other experiences during their trip. The focus of the study was to understand the sounds climbers recalled hearing during their climbing experience.

\section{Phase two: Listening exercise and survey}

This study used methods commonly applied to other studies that examine the effects of human caused noise on visitors to protected areas (Kariel 1990, Marin et al. 2011, Pilcher et al. 2009, Taff et al. 2015). Respondents were asked to participate in the exercise during their descent from the Grand Teton at one of two different locations: near the Meadows site or the 3-Mile Junction. They were instructed by the researchers to close their eyes and listen to the sounds around them for two minutes, then use the iPad survey to indicate what sounds were heard and to rate whether the sounds were pleasing or annoying and the acceptability of the sounds heard. For example, a respondent may hear other people talking and rate it as annoying, but also rate it as highly acceptable given the location. 
Sampling at the two locations took place between July 13 and August 10,2015, a time period of high climbing use on the Grand Teton. There was an $89 \%$ response rate with at total $n=234$. Sampling at 3 Mile Junction took place from July 13 to August 10, 2015, with a total $n=122$. Sampling at the Meadows took place from July 19 to August 9, 2015 with a total $n=112$.

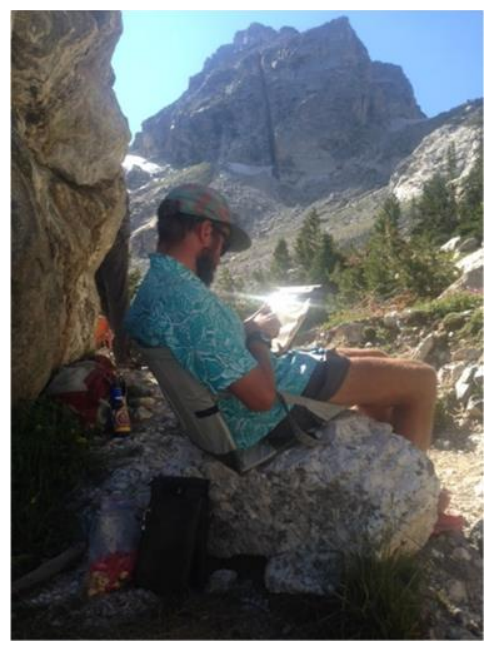

Figure 4. A climber completing the listening exercise at the Meadows Site.

\section{$\downarrow \quad$ RESULTS}

Phase one: Climber qualitative interviews

The climbers interviewed ranged in age from 23 to 60 , and all but one party were from the United States. We interviewed one climbing party from Canada. Climbers ranged in self-described experience from beginner to professional, and in years of climbing experience with one climber having 3 days of experience and others having 40 plus years. Eleven climbers had climbed the Grand Teton for the first time and 7 were return climbers. The majority of parties climbed on the Owen Spalding route, one party climbed the Black Ice Couloir and the East Ridge. Other parties climbed on the Upper Exum Ridge and Direct Petzoldt Ridge. The following semi-structured interview results describe information about the sounds climbers recall hearing during their climbing experience.

First we asked what kind of sounds they heard during their trip. Eight of the parties interviewed mentioned hearing aircraft. Three of the parties that heard aircraft mentioned that it sounded like thunder. The following are examples of the responses we received:
Int 2: Other than wilderness sounds, there were a lot of birds, did hear a couple of planes, saw a helicopter, flew by the saddle at some point. That was most of it. You could hear some people's electronic devices at some point, as well, which was kind of annoying. (Interviewer) What kind of electronic devices? (Climber 1) Oh, like their cellphone, or something else. (Interviewer) Like a cellphone ringing? (Climber 1)Yeah, some people would bring their cellphones up to the saddle. Evidently, a lot of people had fairly good reception up there. I think that defeats kind of the whole purpose of going up into the mountains, so, yeah.

Int.9: (Climber 2) Airplanes. It was startling. I was like oh I guess the airports really close. (Climber 1) Yeah and it can sound like thunder or rock fall, the initial loud noise is a real concern because I spend so much time on the mountains. I get startled. Yeah the jets. And part of the Marian was collapsing. That made us jump but it was probably just a big boulder shifting.

Int. 12: (Climber 1) Rock fall, hail, cracking my helmet, high winds blowing through. (Climber 2) Marmots chirping. (Climber 1) Thunder and lightning, certainly the sound of running water, the beauty of a creek or a small river running is very pleasant. I guess the other sound is just the sound your feet make, especially in a snowfield, just listening to the sounds your feet make.

Next we asked what sounds they enjoyed hearing. The following are examples of common responses:

Int. 5: I like the drowning sound of the falls a little bit. It's far enough, sometimes it can be, uh, it can break up communication, but it was just a faint noise so it was kind of nice, peaceful.

Int. 8: I always enjoy hearing, uh, gear placements in rock, like it's just an enjoyable sound, so in the couple technical pitches we did, um, just hearing carabiners click and ropes, you know, running through carabiners and, you know, all the climbing sounds.

Int. 18: (Climber 1) Aw I like all the sounds up there, I like the sounds of the avalanches and the rocks falling it's just something primal about it. (Climber 2) I like the water (Climber 1) You an avalanche coming down and *inaudible * it's like a present for climbers. More rock falling.

Subsequently, we asked respondents what sounds they enjoyed hearing the least. The following are examples of common responses:

Int. 3: The sound I enjoy hearing the least is the dude screaming 'rock!' as he kicked that thing off, but like on days off it's nice to not hear other people and just go climb. You know? You don't have to hear questions 
like, 'oh, what routes are you guys doing? Oh, was it cool?' you know? Shit like that gets old. I guess you can leave that for work.

Int. 6: Rock fall is a scary one. That's probably mine Int. 10: (Climber 1) The airplanes. (Climber 2) Yeah I mean they didn't bother me that much I was more nervous that it was thunder coming. That's what I enjoyed the least but we were well down by then.

Int. 13: The wind is sickening, like I got tired of that sound. Um, but usually a breeze sounds amazing, I usually love that sound. There are local businesses that fly small planes [inaudible from wind] I get a little weirded out about that too.

Finally, we asked respondents if they specifically heard motorized or other human caused sounds while on or near the summit of the Grand Teton. The following are some examples of the responses we received:

Int. 2: Not at the summit, but up mid-route we could definitely hear planes flying over a couple of times. Int. 7: No. I didn't hear anything up there.

Int. 8: (Climber 1) I don't remember that, I mean, maybe there (Climber 2) We heard other climbers. (Climber 1) Yeah, we definitely heard other climbers, but no aircraft or anything like that that I can remember.

Int. 10: (Climber 2) We heard the helicopter when we were at the summit. Or was it lower down, I'm not sure .(Climber 1) I don't remember.

Not all parties interviewed reached the summit, therefore their question was broader. They were asked if they recalled hearing motorized or human caused sounds during their trip. The following are examples of some of the responses:

Int. 4: (Climber 1) I don't remember any helicopters. Airplanes? No. I mean, I have. Not today. Yeah, with the airport. Some helicopters last time we were up here when me and Joe were coming off the summit there was a rescue going on and there was a helicopter just circling us looking for someone, but not today. I don't think so. (Interviewer) Okay. (Climber 1) Oh, except, you know what? The, um, so I think the Exum Mountain Guides have 2 tents up there, so you can hear them flapping in the wind. (Interviewer) Oh, the tents flapping? (Climber 1) Yeah, when you walk past them, it's just a chaotic tent going at it. So, yeah, there's that up there.

Int. 17: Actually yeah, I heard maybe a jet going over because of the airport being so close. But that was it and it was only once.

\section{Phase two: Listening exercise and survey}

Of the 243 climbers that participated in the listening exercise between July 13 and August 10, $2015,79 \%$ of the sample were male and $21 \%$ were female and the average age was 33 years old. Twentythree percent were guided climbers, $72 \%$ were climbing with private parties and 5\% identified themselves as climbing guides. Sixty-four percent rated themselves as intermediate or advanced climbers, and $70 \%$ of climbers were on overnight trips.

During this portion of the study to identify potential soundscape indicators, respondents were asked whether they would be willing to participate in a listening study. Willing participants listened to the sounds around them for two minutes, and then completed an IPad survey. The results of this sample are presented below. Table 1 provides the five most frequently heard natural sounds at 3 Mile Junction. Wind and bird song were heard most frequently, as $88 \%$ of respondents indicated hearing these sounds. Acceptability of sounds were based on a 9-point scale $(-4=$ Very Unacceptable; $0=$ Neutral; $4=$ Very Acceptable) and personal interpretation of sounds were based on a 9-point scale $(-4=$ Very Annoying; 0 $=$ Neutral; $4=$ Very Pleasing). The sound of wind was, on average, perceived as acceptable $(M=2.8)$ and very pleasing $(M=3.0)$. Bird song was perceived as very acceptable $(M=3.2)$ and very pleasing $(M=3.3)$. Wind rustling in the trees was the second most frequently heard sound. Eighty-five percent of respondents indicated that they heard wind rustling in the trees, on average these respondents found the sound to be acceptable $(M=2.8)$ and very pleasing $(M=3.2)$. Eighty-four percent of respondents at 3 Mile Junction heard insects, and mean acceptability dropped considerably compared to the sounds of wind or bird song. These respondents indicated that insect sounds were still acceptable $(M=2.2)$, but annoying $(M=-0.3)$. Finally, water was heard by $62 \%$ of respondents, and considered acceptable $(M=1.8)$ and very pleasing $(M=3.4)$.

Table 2 provides the five most frequently heard anthropogenic sounds at the 3 Mile Junction site. Walking sounds were heard most frequently, as $78 \%$ of respondents indicated hearing this sound. Walking sounds was, on average, perceived as acceptable $(M=2.5)$ and slightly pleasing or almost neutral $(M=0.8)$. Voices were heard by $76 \%$ of respondents and were perceived as slightly acceptable $(M=1.7)$ and slightly pleasing or almost neutral $(M=0.4)$. Sixtythree percent of respondents indicated that they heard vehicles (other than motorcycles). The sounds of 
Table 1. 3-Mile Junction climber evaluation of the five most frequently heard natural sounds

\begin{tabular}{|c|c|c|c|c|c|c|c|}
\hline \multicolumn{2}{|c|}{ Sound Heard } & $n$ & $\begin{array}{c}\text { Percent } \\
\text { Heard }\end{array}$ & $\begin{array}{c}\text { Mean }^{1} \\
\text { Acceptability }\end{array}$ & $\begin{array}{c}\text { SD } \\
\text { Acceptability }\end{array}$ & $\begin{array}{c}\text { Mean }^{2} \\
\text { Personal } \\
\text { Interpretation }\end{array}$ & $\begin{array}{l}\text { SD Personal } \\
\text { Interpretation }\end{array}$ \\
\hline 1. & Wind & 107 & 88 & 2.8 & 1.7 & 3.0 & 1.7 \\
\hline 2. & Bird song & 107 & 88 & 3.2 & 1.2 & 3.3 & 1.2 \\
\hline 3. & $\begin{array}{l}\text { Wind rustling in } \\
\text { the trees }\end{array}$ & 104 & 85 & 2.8 & 1.7 & 3.2 & 1.1 \\
\hline 4. & Insects & 102 & 84 & 2.2 & 2.2 & 0.3 & 2.8 \\
\hline 5. & $\begin{array}{l}\text { Water, streams, } \\
\text { rivers, etc. }\end{array}$ & 75 & 62 & 1.8 & 2.1 & 3.4 & 1.1 \\
\hline
\end{tabular}

${ }^{1}$ Acceptability based on 9-point scale (-4 = Very Unacceptable; $0=$ Neutral; 4 = Very Acceptable)

${ }^{2}$ Personal interpretation based on 9-point scale ( $-4=$ Very Annoying; $0=$ Neutral; 4 = Very Pleasing)

Table 2. 3-Mile Junction climber evaluation of the five most frequently heard anthropogenic sounds

\begin{tabular}{lcccccc}
\hline Sound Heard & $n$ & $\begin{array}{c}\text { Percent } \\
\text { Heard }\end{array}$ & $\begin{array}{c}\text { Mean }^{1} \\
\text { Acceptability }\end{array}$ & $\begin{array}{c}\text { SD } \\
\text { Acceptability }\end{array}$ & $\begin{array}{c}\text { Mean }^{2} \\
\text { Personal } \\
\text { Interpretation }\end{array}$ & $\begin{array}{c}\text { SD } \\
\text { Interpretation }\end{array}$ \\
\hline 1. $\quad$ Walking & 95 & 78 & 2.5 & 1.9 & 0.8 & 1.9 \\
2. Voices & 93 & 76 & 1.7 & 2.3 & 0.4 & 1.9 \\
3. $\quad$ Vehicles & 77 & 63 & -0.3 & 2.6 & -1.3 & 2.5 \\
4. $\quad$ Climbing Gear & 68 & 56 & 2.0 & 2.0 & 0.9 & 1.8 \\
5. $\quad$ Jet Aircraft & 64 & 53 & -0.2 & 2.6 & -1.3 & 2.4 \\
\hline
\end{tabular}

${ }^{1}$ Acceptability based on 9-point scale (-4 = Very Unacceptable -4 = Very Acceptable)

${ }^{2}$ Personal interpretation based on 9-point scale (-4 = Very Annoying $-4=$ Very Pleasing $)$

vehicles were, on average, considered neutral in terms of acceptability $(M=-0.3)$ and slightly annoying $(M=-$ 1.3). The sounds associated with climbing gear were perceived as acceptable $(M=2.2)$ and almost neutral concerning whether those sounds were annoying or pleasing $(M=0.9)$. Fifty-three percent of respondents indicated hearing jet aircraft, on average these sounds were just barely unacceptable $(M=-0.2)$, but annoying $(M=-1.3)$.

Table 3 provides the five most frequently heard natural sounds at the Meadow site. The sounds of water, streams, rivers, etc., were heard most frequently, as $98 \%$ of respondents indicated hearing this sound. These sounds, on average, were perceived as very acceptable $(\mathrm{M}=3.6)$, and very pleasing $(\mathrm{M}=3.4)$. Wind was the second most frequently heard sound. Ninety-six percent of respondents indicated that they heard wind and, on average, these respondents found the sound to be acceptable $(M=2.8)$ and pleasing $(M=2.6)$. Eighty-one percent of respondents at the Meadows site heard wind rustling in the trees and indicated that these sounds were acceptable $(M=2.6)$ and pleasing $(M=2.8)$. Birdsong was heard by $66 \%$ of respondents, and considered acceptable $(M=2.7)$ and very pleasing $(M=3.2)$. Finally, mammals were heard by $38 \%$ of respondents, and they indicated that the sounds were acceptable $(M=1.9)$ and pleasing $(M=2.4)$.

Table 4 provides the five most frequently heard anthropogenic sounds at the Meadows site. Voices were heard most, by $77 \%$ of respondents. These sounds were slightly acceptable $(M=1.3)$, but slightly annoying as well $(M=-0.03)$. Walking sounds, which were heard by $74 \%$ of respondents, were perceived as acceptable $(M=2.3)$, but slightly pleasing $(M=0.6)$. Fifty-two percent of respondents indicated that they heard climbing gear, and, on average, considered these sounds to be acceptable $(M=1.7)$ and slightly pleasing $(M=0.8)$. Jet aircraft were heard by $30 \%$ of respondents. These sounds were found to be slightly unacceptable $(M=-1.0)$ and slightly annoying $(M=-1.5)$. Twenty-seven percent of respondents indicated hearing propeller aircraft, and, on average, these sounds were just slightly unacceptable $(M=-0.9)$ and annoying $(M=-1.4)$. 
Table 3. The Meadow Site climber evaluation of the five most frequently heard natural sounds

\begin{tabular}{|c|c|c|c|c|c|c|c|}
\hline \multicolumn{2}{|c|}{ Sound Heard } & $n$ & $\begin{array}{l}\text { Percent } \\
\text { Heard }\end{array}$ & $\begin{array}{c}\text { Mean }^{1} \\
\text { Acceptability }\end{array}$ & $\begin{array}{c}\text { SD } \\
\text { Acceptability }\end{array}$ & $\begin{array}{c}\text { Mean }^{2} \\
\text { Personal } \\
\text { Interpretation }\end{array}$ & $\begin{array}{c}\text { SD } \\
\text { Personal } \\
\text { Interpretation }\end{array}$ \\
\hline 1. & Water & 110 & 98 & 3.6 & 1.8 & 3.4 & 1.1 \\
\hline 2. & Wind & 107 & 96 & 2.8 & 1.7 & 2.6 & 1.6 \\
\hline 3. & $\begin{array}{l}\text { Wind rustling } \\
\text { in the trees }\end{array}$ & 91 & 81 & 2.6 & 1.9 & 2.8 & 1.6 \\
\hline 4. & Birdsong & 74 & 66 & 2.7 & 2.0 & 3.2 & 1.2 \\
\hline 5. & Mammals & 42 & 38 & 1.9 & 2.3 & 2.4 & 1.8 \\
\hline
\end{tabular}

${ }^{1}$ Acceptability based on 9-point scale (-4 = Very Unacceptable; $0=$ Neutral; 4 = Very Acceptable)

${ }^{2}$ Personal interpretation based on 9 -point scale $(-4=$ Very Annoying; $0=$ Neutral; $4=$ Very Pleasing)

Table 4. The Meadow Site climber evaluation of the five most frequently heard anthropogenic sounds

\begin{tabular}{|c|c|c|c|c|c|c|c|}
\hline \multicolumn{2}{|c|}{ Sound Heard } & $n$ & $\begin{array}{c}\text { Percent } \\
\text { Heard }\end{array}$ & $\begin{array}{c}\text { Mean }^{1} \\
\text { Acceptability }\end{array}$ & $\begin{array}{c}\text { SD } \\
\text { Acceptability }\end{array}$ & $\begin{array}{c}\text { Mean }^{2} \\
\text { Personal } \\
\text { Interpretation }\end{array}$ & $\begin{array}{l}\text { SD Personal } \\
\text { Interpretation }\end{array}$ \\
\hline 1. & Voices & 86 & 77 & 1.3 & 2.1 & -0.3 & 19 \\
\hline 2. & Walking & 83 & 74 & 2.3 & 1.8 & 0.6 & 2.0 \\
\hline 3. & $\begin{array}{l}\text { Climbing } \\
\text { Gear }\end{array}$ & 58 & 52 & 1.7 & 1.9 & 0.8 & 2.3 \\
\hline 4. & Jet Aircraft & 33 & 30 & -1.0 & 2.0 & -1.5 & 1.7 \\
\hline 5. & $\begin{array}{l}\text { Propeller } \\
\text { Aircraft }\end{array}$ & 30 & 27 & -0.9 & 2.2 & -1.4 & 1.8 \\
\hline
\end{tabular}

${ }^{1}$ Acceptability based on 9-point scale (-4 = Very Unacceptable $-4=$ Very Acceptable)

${ }^{2}$ Personal interpretation based on 9-point scale $(-4=$ Very Annoying $-4=$ Very Pleasing $)$

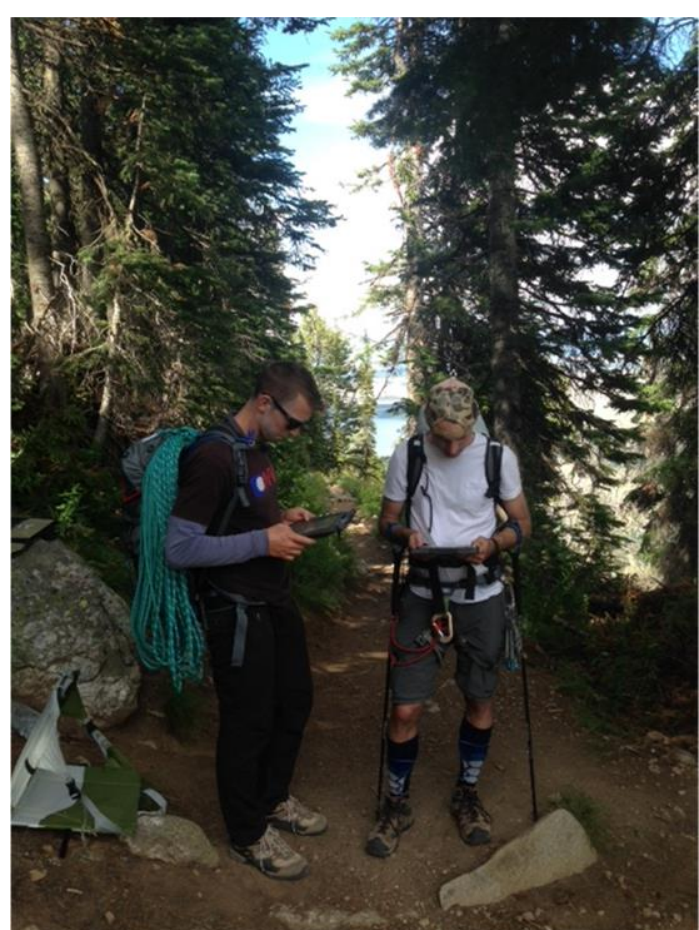

Figure 4. Climbers completing the listening survey at the 3Mile Junction Site.
Tables 5 and 6 provide combined results from the 3 Mile Junction and the Meadows sites. Table 5 provides the five most frequently heard natural sounds. Wind was heard by $91 \%$ of climbers and was rated at acceptable $(M=2.8)$ and pleasing $(M=2.8)$. Eighty three percent of climbers heard wind rustling in the trees. This sound was rated as acceptable $(M=2.7)$ and very pleasing $(M=3.0)$. Water, streams, or rivers were heard by $79 \%$ of climbers and was rated as acceptable $(M=2.9)$ and very pleasing $(M=3.4)$. Birdsong was heard by $77 \%$ of respondents and was rated as very acceptable $(M=3.0)$ and very pleasing $(M=3.2)$. Finally, insects were heard by $62 \%$ of climbers and was rated as acceptable $(M=2.0)$ and interpreted as neither pleasing nor annoying $(M=0.7)$.

Table 6 provides the five most commonly hear anthropogenic sounds. Voices were heard most frequently with $76 \%$ of climbers reporting they were slightly acceptable $(\mathrm{M}=1.4)$ and interpreted as very slightly pleasing $(\mathrm{M}=0.9)$. Walking sounds were also heard most frequently with $76 \%$ of climbers reporting them as acceptable $(\mathrm{M}=2.4)$ and interpreted as neutral $(\mathrm{M}=0.7)$. The third most frequently heard sound was climbing gear. Fifty four percent of climbers heard this sound and reported it as acceptable $(\mathrm{M}=1.9)$ and 
Table 5. Overall climber evaluation of the five most frequently heard natural sounds

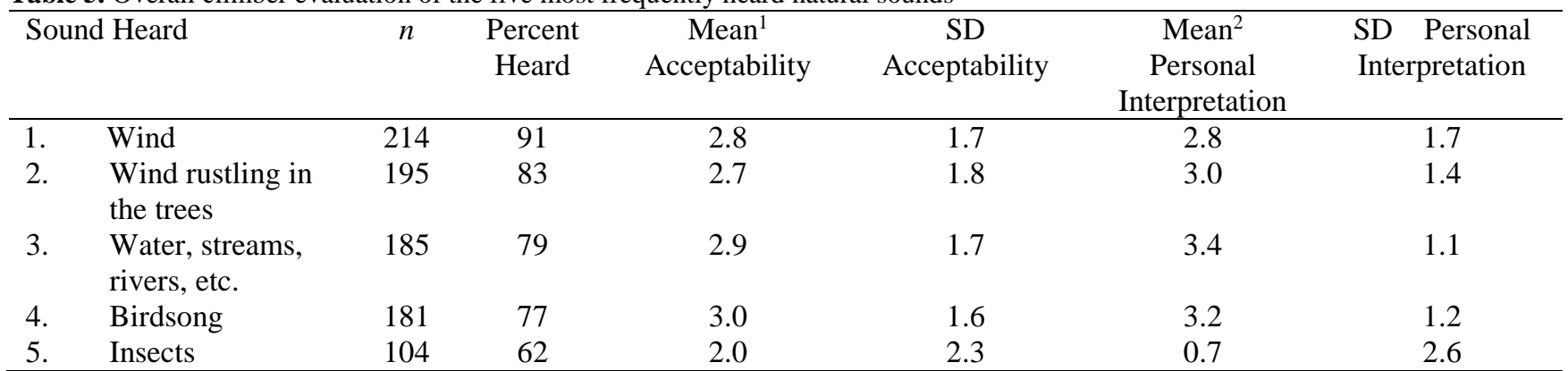

${ }^{1}$ Acceptability based on 9-point scale (-4 = Very Unacceptable; $0=$ Neutral; 4 = Very Acceptable)

${ }^{2}$ Personal Interpretation based on 9-point scale (-4 = Very Annoying; $0=$ Neutral; 4 = Very Pleasing)

Table 6. Overall climber evaluation of the five most frequently heard anthropogenic sounds

\begin{tabular}{llcccccc}
\hline Sound Heard & $n$ & $\begin{array}{c}\text { Percent } \\
\text { Heard }\end{array}$ & $\begin{array}{c}\text { Mean } \\
\text { Acceptability }\end{array}$ & $\begin{array}{c}\text { SD } \\
\text { Acceptability }\end{array}$ & $\begin{array}{c}\text { Mean }^{2} \\
\text { Personal } \\
\text { Interpretation }\end{array}$ & $\begin{array}{c}\text { SD } \\
\text { Interpretation }\end{array}$ \\
\hline 1. & Voices & 179 & 76 & 1.4 & 2.2 & 0.9 & 1.9 \\
2. & Walking & 178 & 76 & 2.4 & 1.8 & 0.7 & 1.9 \\
3. & Climbing & 126 & 54 & 1.9 & 2.0 & 0.9 & 2.0 \\
& $\quad$ Gear & & & & & & \\
4. & Jet Aircraft & 97 & 41 & -0.5 & 2.4 & -1.3 & 2.1 \\
5. & Vehicles & 95 & 40 & -0.5 & 2.5 & -1.5 & 2.3 \\
\hline
\end{tabular}

${ }^{1}$ Acceptability based on 9-point scale (-4 = Very Unacceptable -4 = Very Acceptable)

${ }^{2}$ Personal Interpretation based on 9-point scale $(-4=$ Very Annoying $-4=$ Very Pleasing

interpreted it as neutral or slightly pleasing ( $M=0.9)$. Jet aircraft, the fourth most frequently heard sound, was heard by $41 \%$ of climbers and was rated as neutral or almost slightly unacceptable $(\mathrm{M}=-0.5)$. Jet aircraft was interpreted as annoying ( $M=-1.3)$. Finally, vehicles were heard by $40 \%$ of climbers and was reported as neutral or almost slightly unacceptable $(\mathrm{M}=-0.5)$ and interpreted as annoying $(\mathrm{M}=-1.5)$.

\section{MANAGEMENT IMPLICATIONS}

This study was successful in identifying baseline data regarding the sounds heard by climbers during their experience on the Grand Teton, as well as their perceptions of sounds. The qualitative interviews provided the following information:

- Eight of the 18 interviews mentioned hearing aircraft when asked generally about sounds they remember hearing during their climb.

- Waterfalls, gear placement and avalanche are examples of sounds climbers enjoyed hearing the most.

- Rock fall, airplanes and wind are examples of sounds climbers enjoyed hearing the least.

The listening exercise identified sounds heard by climbers and their evaluation of sounds (See Tables 5 and 6). Results from the listening exercise $(\mathrm{n}=234)$ indicated:

- Jet aircraft was the fourth most frequently heard anthropogenic sound. Forty one percent of climbers rated the sound as slightly unacceptable and annoying.

- Vehicle sounds were the fifth most frequently heard anthropogenic sound, with $40 \%$ of climbers rating it as slightly unacceptable and annoying.

These sounds signify a priority for managers to address, given the substantial number of climbers who reported hearing these sounds and their negative evaluation. A majority of climbers heard wind (91\%), wind rustling the trees $(83 \%)$, water $(79 \%)$, birdsong $(77 \%)$, voices $(76 \%)$, and walking $(76 \%)$. The natural sounds were rated as acceptable and pleasing, while voices and walking were rated as acceptable but were interpreted as neither pleasing nor annoying. These results identify climbers' positive evaluation of natural sounds.

The purpose of this study was to provide managers with information about the sounds climbers are hearing during their experience on the Grand 
Teton. These data can aid in informing a future visitor survey. The future survey would aim to identify a threshold that indicates when anthropogenic sounds, such as jet aircraft and vehicle sounds, become unacceptable in a way that negatively impacts visitor experience.

\section{ACKNOWLEDGEMENTS}

In addition to support from the UW-NPS Research Station, this project received funding from the Grand Teton Association through the Boyd Evison Fellowship for the Greater Yellowstone Ecosystem. We would also like to thank Shan Burson for his guidance and support with the project, as well as Ian Hopkins for his work as a dedicated research assistant. Additionally, we would like to thank Scott Gunther and the GRTE climbing rangers for their backing of the project, as well as those affiliated with the Grand Teton Climbers' Ranch, especially William Fetterhof and Debbie and Gary Bunten. Finally, we would like to thank Nat Patridge and the Exum Guides for their good spirits and support throughout the project.

\section{$\uparrow \quad$ Literature Cited}

Driver, B.L., R. Nash, and G. Haas. 1987. Wilderness benefits: A state-of-knowledge view. In: Proceedings, National Wilderness Research Conference: Issues, State of Knowledge, Future Directions. Fort Collins, CO, compiled by R.C. Lucas, USDA Forest Service General Technical Report INT-220: 294-329.

Kariel, H. G. 1990. Factors affecting response to noise in outdoor recreational environments. The Canadian Geographer 34:142-149.
Lynch, E., D. Joyce, and K. Fristrup. 2011. An assessment of noise audibility and sound levels in US National Parks. Landscape Ecology 26:1297-1309.

Marin, L. D., P. Newman, R.E. Manning, J.J. Vaske, and D. Stack. 2011. Motivation and acceptability norms of human-caused sound in Muir Woods National Monument. Leisure Sciences 33:147 - 161 .

Monz, C. A. 2009. Climbers' attitudes toward recreation resource impacts in the Adirondack Park's Giant Mountain Wilderness. International Journal of Wilderness 15: 26-33.

Newman, P.B., B. Taff, J. Newton, and L. Abbott. 2015. Informing visitor use management strategies for the Moose-Wilson Corridor, Grand Teton National Park. Pennsylvania State University, Protected Areas Research Cooperative, University Park, PA.

National Park Service. 2006. National Park Service Management Policies. U.S. Government Printing Office. ISBN 0-16-076874-8.

Pilcher, E. J., P. Newman, and R.E. Manning. 2009. Understanding and managing experiential aspects of soundscapes at Muir Woods National Monument. Environmental Management, 43:425-435.

Taff, B. D., D. Weinzimmer, and P. Newman. 2015. Mountaineers' wilderness experience in Denali National Park and Preserve. International Journal of Wilderness.

Tarrant, M. A., G.E. Haas, and M.J. Manfredo. 1995. Factors affecting visitor evaluations of aircraft overflights of wilderness areas. Society and Natural Resources 8:351-360.

Wilderness Act, Definition of Wilderness, Section 2.(c). 1964. Public Law 88 - 577. 1131 1136. 